$\checkmark$ sciendo $\frac{\text { ECONOMIC THEMES (2020) 58(1): 33-52 }}{\text { DOI 10.2478/ethemes-2020-0003 }}$

\title{
TWO-PHASE EXPONENTIAL MODEL OF WEALTH DISTRIBUTION
}

\author{
Ognjen Radović \\ University of Nis, Faculty of Economics, Republic of Serbia \\ \ognjen.radovic@eknfak.ni.ac.rs \\ Zoran Tomić \\ University of Niš, Agricultural Faculty, Republic of Serbia \\ $\bowtie$ tomic.zoran@ni.ac.rs \\ Jelena Z. Stanković \\ University of Nis, Faculty of Economics, Republic of Serbia \\ $\bowtie$ jelenas@eknfak.ni.ac.rs \\ UDC \\ 330.54 \\ Original \\ scientific \\ paper

\begin{abstract}
The topic of wealth and money distribution attracts great attention of economists, as well as researchers from other scientific fields, such as statistical physics and econophysics. An increasing number of models and simulations are being created in order to understand the process of wealth distribution and reaching the steady state of the distribution system. Also, the number of papers dealing with analysis and determining the distribution proportion is constantly growing, and, unlike the previous years, when the Pareto principle was " $80-20$ ", today that principle could be "90-10"and even "90-20". In this paper we present an agent-based simulation model derived from econophysics that describes the dynamics of wealth distribution. Two models of exponential function are tested: a one-phase model that uses the Newton's law of cooling and a two-phase exponential function model. We found that exponential decreasing function adequately described the dynamics of wealth distribution, especially in the models without the possibility of borrowing money, and the validity of the Pareto principle " $80-20$ " in these models could be confirmed.
\end{abstract}

Received: 20.02.2020 Accepted: 28.04.2020
Keywords: wealth distribution, exponential functions, Newton's law of cooling

JEL classification: D31, G51, C63, E47 


\section{Introduction}

In economics, the state of the economic system in which supply of goods by producers equals demand for goods by consumers on every market at any point of time is considered as equilibrium. The equilibrium of a competitive market can be studied from a partial or general equilibrium perspective. Analysing economic equilibrium from partial perspective implies considering one market and only direct effects, while assuming that indirect and effects from other markets can not affect interactions among participants on observed market. On the other hand, the general equilibrium considers the whole economy as a closed system of interdependent markets and variety of economy-wide interactions affected by direct, indirect and induced effects. Since it is commonly assumed that all market participants own identical initial wealth and behave identically in the observed period, the characteristics of wealth distributions are not considered significant for competitive economy equilibrium. However, distribution of wealth can have influence on dynamic evolution of GDP per-capita in the long-term period (Sorger, 2000).

Considering the fact that the distribution of earnings and wealth in most countries is becoming notably unequal, the interest in the various models that can generate the statistical properties of earnings and wealth distributions has increased (Hubmer et al., 2016). In addition to an empirical analysis of the current state and the problem of uneven distribution of wealth, numerous models are created, which can verify the process of evolution and the formation of the equilibrium state in the allocation of wealth. The advanced computer technology enabled researchers to study this issue in a computational agent-based framework, which can identify determinants of wealth distribution in economies (Lux, 2005). Xiong et al. (2017) simulated the creation of money and its circulation model in an economy, when there was a possibility of borrowing. Drăgulescu and Yakovenko (2001) simulated distribution of money, income and wealth and they concluded that the distribution could be described by the Boltzmann-Gibbs model. However, income and wealth distributions are often described as positively skewed and thick-tailed (Wang, 2007; Benhabib \& Bisin, 2018). The Pareto power-law distribution is a consequence of the fundamental characteristics of the capital market, its efficiency and wealth accumulation (Klass et al., 2006). The Pareto Principle is a rationalized expression of the mathematics behind the Pareto distribution, and it states that in the cases of most phenomena $80 \%$ of outputs are produced by $20 \%$ of inputs or even " $90-10$ " or "90-20" (Dunford et al., 2014).

According to Dixon (1990) three basic principles of equilibrium need to be fulfilled: (1) behaviour of agents is consistent, (2) no agent has the initiative to change their behaviour, and (3) the equilibrium is the result of a dynamic process. Based on these principles and using the agent-based simulation model, we model the distribution of wealth between the agents. Assuming that the agent-based modeling could simulate actions and interactions between the agents, as well as 
their effects on the system by using the law of cooling, the aim of this research is to test the performance of two exponential functions in revealing the dynamics of change in the relationship between the wealth proportions of the poorest $80 \%$ of the population and $20 \%$ of the richest. Therefore, in the second part of the paper the agent-based modelling will be described, while the implemented models will be presented in the third part of the paper. The achieved results will be presented in the fourth part. The paper concludes the performance of the models in the last part.

\section{The agent-based models}

Agent-based modelling (ABM) and simulations (ABMS) are relatively new paradigms in the computer modelling and simulation of complex systems (Macal \& North, 2010). The main component of the model is agent, whose behaviour is modelled individually considering that each agent is independent of others. If all the agents have relatively similar characteristics, such a system can be specified as a system with homogeneous agents. However, complex systems usually consist of components of different properties, so the most adequate models for modelling such systems are models with heterogeneous agents. In the process of system modelling, ABM uses the bottom-up approach (Wooldridge, 2009). Firstly, the basic components - agents, are modelled, and then, hierarchically, groups of agents and their relationships in the groups, as well as the environment and the features of interaction between agents and groups of agents and the environment. The modelling of the interactions between the agents, on one hand, and their interactions with the environment, on the other, connects the micro-level of agents with the macro-level of the environment and the system (Wooldridge, 2009; Wilensky \& Rand, 2015). Specifically, out of these interactions a complex behaviour of agents evolves and it cannot be induced from individual characteristics of agents.

Wide acceptance of ABMS and its advantage over classical techniques of mathematical modelling (equation-based modelling) may be attributed to the following properties (Michel et al, 2018; Leys 2019): (a) the ABM is a flexible model that can be easily modified by adding new properties to the agents, environment and interactions; (b) ABMS has precise control over the flow of the simulation; (c) ABM does not exclude the individual features, behaviour, and the interactions of the system components; (d) it is relatively easy to create artificial, computer, microworld with the ability to control all the features of the model and support a wide variety of simulation.

Trichet, the former President of the European Central Bank, referred to the importance of ABMS approach for modelling complex economic and financial system (Trichet, 2010): "When the crisis came, the serious limitations of existing economic and financial models immediately became apparent ... Macro models failed to predict the crisis and seemed incapable of explaining what was happening to the economy in a convincing manner ... We need to entertain alternative 
motivations for economic choices. Behavioural economics draws on psychology to explain decisions made in crisis circumstances. Agent-based dispenses with the optimization assumption and allows for more complex interactions between agents. Such approaches are worthy of our attention".

Regarding the ABMS approach, we consider the simplest example of a closed economy. In this economy, there are a total of $N$ number of economic agents that have a total amount of money $M$. In this model, the production of new goods or emissions of additional amounts of money are not allowed, but the agents trade by pre-defined rules. Let the agent $i$ in a given time $t$ has the amount of money $m_{i}(t)$. When the two agents trade, a law of conservation of money applies, i.e. the total amount of money that two agents would possess after the trade would be equal to the total amount of money they had before the trade, which could be explained in the following manner:

$$
\begin{gathered}
m_{i}(t)+\Delta m=m_{i}(t+1) \\
m_{j}(t)-\Delta m=m_{j}(t+1) \\
m_{i}(t)+m_{j}(t)=m_{i}(t+1)+m_{j}(t+1)
\end{gathered}
$$

where $\Delta m$ represents the value of the realized transaction.

In this model lending is not allowed, so after each trade agents will have the amount of money that is greater or equal to zero, i.e. $m_{i}(t) \geq 0$, while the total amount of money in the economy is constant, i.e. $\sum_{i=1}^{N} m_{i}=M$. Since the requirement of maintaining the stable quantity of money is fulfilled $(t \rightarrow \infty)$, it can be applied that probability that the agent has an amount of money $m$ is

$$
P\left(m_{1}\right) P\left(m_{2}\right)=P\left(m_{1}+m_{2}\right)
$$

Agents who have 0 quantity of money cannot buy goods from other agents, but can receive the money from the agents for the delivery of their goods.

The authors of many studies confirmed that the probability distribution and cumulative probabilities for these models can be described by the Boltzmann-Gibbs distribution usually applied in physics (Yakovenko, 2010). A fundamental law of equilibrium in statistical physics is the Boltzmann-Gibbs law, which states that the probability $P(\varepsilon)$ to find a physical system or subsystem with the state of energy $\varepsilon$ is determined by the following exponential function (Yakovenko, 2010):

$$
P(\varepsilon)=c \cdot e^{-\frac{\varepsilon}{T}}
$$

where $c$ represents a normalization constant, and $T$ is a temperature that is equal to the average energy per particle. The probability $P(\varepsilon)$ will not be more than 1 . The presented equation will function in the system if the law of conservation of energy 
applies, i.e. the sum of the energy in the system, which is constant, is equal to the sum of the individual particles' energy, as well as that the probability that the particle has the energy equal to the sum of energies' of two particles is equal to the product of probabilities that particles have the specified energy. Drăgulesku and Yakovenko (2010) used the Boltzmann-Gibbs distribution to describe the distribution of money between agents in the following manner:

$$
P(m)=c \cdot e^{-\frac{m}{T}}
$$

where $m$ represents the amount of money that each agent has, $T$ is the „money temperature ", which is equal to the average value of the money that each agent has. Drăgulesku and Yakovenko (2001) have shown that this model can be applied in order to describe the distribution of money and income in USA and UK. Based on the derivation of the distribution function it can be concluded that the normalization constant equals to the reciprocal value of money temperature.

The basic model is not realistic, because there is no world economy where trade is conducted only with a certain amount of money, without the possibility of borrowing. This model is very difficult to achieve, because it would imply that economic agents have to provide a sufficient amount of money to be able to engage in the process of trade. The model may be closer to reality if the agents are allowed to borrow money.

Therefore, in order to make this model a closer representation of reality, we introduce a new term - the agents can borrow money from the bank without interest. In our model agents are allowed to borrow a maximum amount of their initial amount of money in order to trade, but not to create new products. During the observed process of trading not all agents will exploit fully the right to borrow money, but only the ones who need additional amounts of money to carry out the trade. In mathematical terms each of the agents will have an additional amount $m_{d}$ of money which they can use. Agents on their balance can have a negative value, but it will not go below overdraft, i.e. $m_{i}(t) \geq-m_{d}$. In this model, the total amount of money available in the economy system is equal to:

$$
M=M_{d}+M_{\text {in }}
$$

what means that the amount of money which agents can use $(M)$ is equal to the sum of additional amount of money $\left(M_{d}\right)$ and initial amount of money $\left(M_{i n}\right)$. The law of conservation of money described by equations 1, 2 and 3 applies in this case, only now the value that an agent can have on their account can be negative.

In this model temperature of money will increase, because there will be additional amount of money in the economy that will be much higher than the initial amount, leading to an increase in the value of this parameter. 


\section{Model description}

In our analysis we use the exponential decay function to determine the dynamics of the distribution of wealth. We analyse the dynamics of change in the relationship between the wealth proportions of the poorest $80 \%$ of the population and $20 \%$ of the richest. We expect that this function will best describe dynamics of change in order to achieve the equilibrium level, which is called the Pareto principle. The analysis applies a single-phase function that represents Newton's law of cooling in physics and a two-phase exponential function that contains two "cooling" processes - one describing a short-term effect and the other describing a long-term effect.

When the warm bodies are left in the open, they gradually begin to cool down. Isaac Newton discovered that the dynamics of cooling is proportional to difference of body temperature in relation to the temperature of surroundings. This observation is called Newton's law of cooling. It was not known whether Newton tried to describe this phenomenon theoretically, but this conclusion arose experimentally (Desai, 2006, pp. 51).

Newton's law of cooling mathematically can be described as a change in the body temperature by time in the following manner:

$$
\frac{d T}{d t}=-k \cdot\left(T-T_{o}\right)
$$

where $T$ represents the temperature of the object under observation at time point, $t$ is the time point, $T_{o}$ represents the temperature of the surroundings and $k$ is the cooling constant which indicates the dynamics of the body cooling. The reciprocal value of the cooling constant is called the time cooling constant. It is equal to the time required that the initial temperature difference falls $e$ times assuming the constant temperature environment. The smaller the value of the time cooling constant, the faster the cooling down process of the body is. By solving the differential equation (8) we get:

$$
\frac{d T}{T-T_{o}}=-k \cdot d t
$$

then the previous equation integrates

$$
\begin{gathered}
\int \frac{d T}{T-T_{o}}=-k \cdot \int d t \\
\ln \left(T-T_{o}\right)=-k \cdot t+C \\
T-T_{o}=e^{-k t} \cdot e^{c} \\
T-T_{o}=A e^{-k t}
\end{gathered}
$$


The equation (10) defines the final form of the formula, which describes the cooling and heating systems of the body. In the equation $T-T_{o}=T_{r e l}$ represents the relative temperature, i.e. the difference between body temperature and surroundings temperature. Parameter $A$ is constant, i.e. $A=e^{c}$. If the value of the constant of proportionality $(k)$ is less than zero then this parameter describes the process of the body cooling down in the surroundings, whose temperature is $T_{o}$ until the temperature of the body is equal to the temperature of the surroundings. If the value of the coefficient of proportionality is greater than zero, then it describes the process of the body warming up in time (Lewis, 2010, pp. 107).

This model can be further developed depending on whether the surroundings temperature is constant or variable. In our study, we use a model with a constant ambient temperature, and a parameter $A$ can be expressed as $A=T_{\text {relo }}=T^{p}-T_{o}{ }^{p}$, i.e. the initial temperature difference between the body and the surroundings when time equals zero. The final form of the model is as following:

$$
T-T_{o}=\left(T^{p}-T_{o}{ }^{p}\right) e^{-k t}
$$

Newton's law of cooling today attracts great attention of many physicists, who deal with the problem of heat conductivity (Vollmer, 2009), as well as economists and econophysicists, who are searching a possible application of this law in the economy. They are primarily concerned with the application of this model to determine the longterm value of the moment of movement of economic indicators, which could serve as additional indicators of successful economic policy and make good business decisions. Michael Lewis (2010) in his work dealt with the problem of application of Newton's law of cooling to describe the dynamics of inflation in the long term, i.e. for predicting the movement of the CPI index, as an indicator of inflation. The author, based on the model, described dynamics of the CPI in the USA for the period from 1913 to 2008 and predicted the values for the first six months in 2009.

Zarikas, Christopoulos and Rendoumis (2009) described the application of Newton's law of cooling in the dynamics of stock indices of the Athens Stock Exchange for several periods of trading. Gkranas, Rendumis and Polatoglu (2003) in their paper described the use of Newton's law of cooling in the case of stock market indices of the Athens and Lisbon exchange markets and introduced the analogy between trading and thermodynamic processes, i.e. processes of rapid heating and cooling to trading on the stock exchange.

The two-phase exponential decreasing function has two components that affect the change of values: short and long term. Both phases, short and long, affect the function value simultaneously, not separately. The function can be used in many different models in chemistry and biology, such as for the determination of the dynamics of the recombination of electrons when observing mutation (Chin et al. 2013) or in the field of photochemistry and photobiology for dynamic analysis of delayed fluorescence ( $\mathrm{Li}$ et al., 2007). The mathematical model is presented in the following manner: 


$$
y=y_{0}+A_{1} e^{-\frac{x}{t_{1}}}+A_{2} e^{-\frac{x}{t_{2}}}
$$

where $y_{o}$ represents the observed value for $x \rightarrow \infty, A_{1}$ and $A_{2}$ are amplitudes and $t_{1}$ and $t_{2}$ are time constants.

\section{Results and discussion}

Based on the application of the above described agent-based model, the trade simulations are carried out between 300,600 and 1,000 agents. The agent-based model is developed in the Netlogo (Wilensky, 2020) programming language and development environment, version 6.1.1. The Netlogo is a tool that is often used when conducting ABMS.

Each agent at the beginning of the simulation gets 1,000 cash units. Moreover, when implementing the simulation, there are established trading rules as follows:

- the first option - the agents have limited amount of money that they could exchange among themselves (the amount of 1,5 or 10 monetary units), but without the possibility of borrowing,

- the second option - the agents could exchange a randomly selected amount of money between 1 and 10 monetary units between themselves, but without the possibility of borrowing,

- the third option - the agents could exchange a randomly selected amount of money between 1 and 10 monetary units between themselves, but with the possibility of borrowing money up to the initial amount of money.

In the following part of the paper we present the results obtained by the analysis of the above trading options. The analyses were conducted in the programme Origin 9.

Figure 1 - Fitted functions for $\mathrm{N}=\mathbf{3 0 0}$, fix $=1$

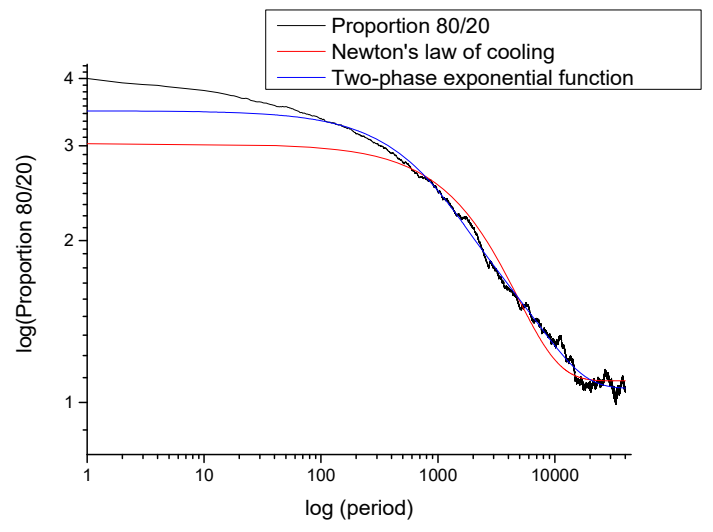

Source: Authors' calculation 
Figure 2 - Fitted functions for $\mathrm{N}=300$, fix $=5$

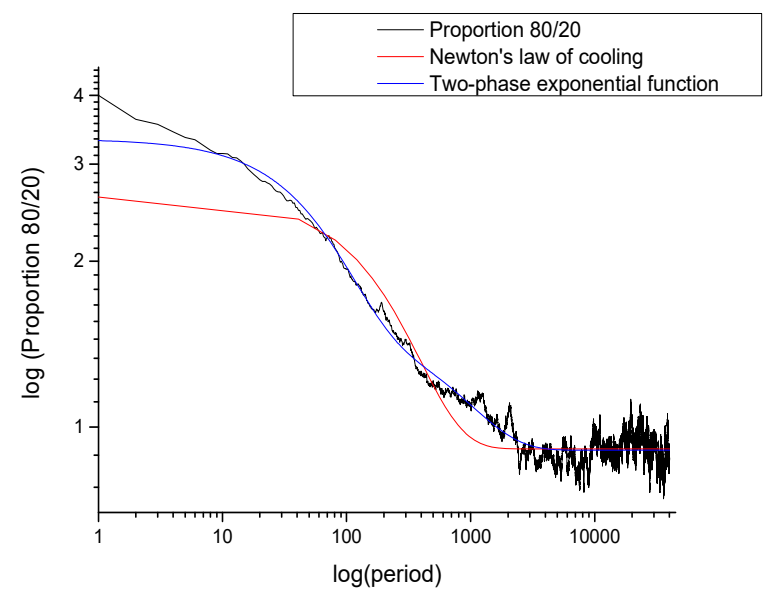

Source: Authors`calculation

Figure 3 - Fitted functions for $\mathbf{N}=\mathbf{3 0 0}$, fix $=10$

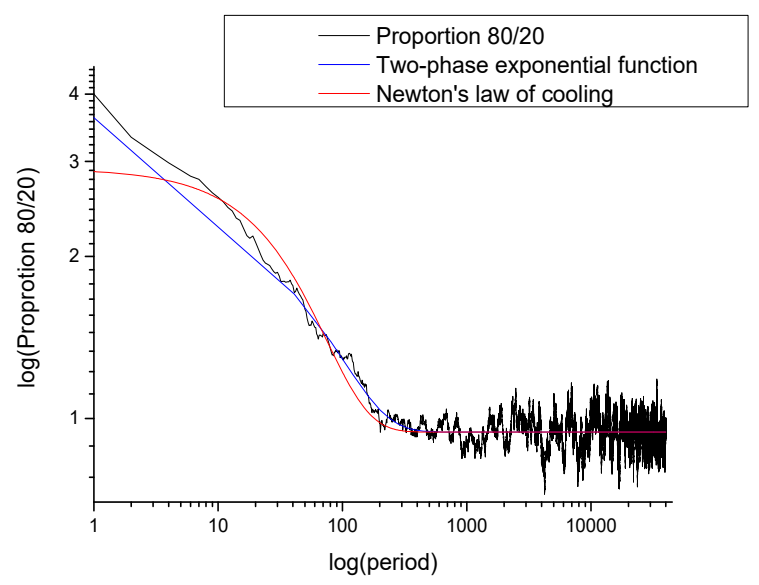

Source: Authors' calculation 
Figure 4 - Fitted functions for $\mathrm{N}=600$, fix $=5$

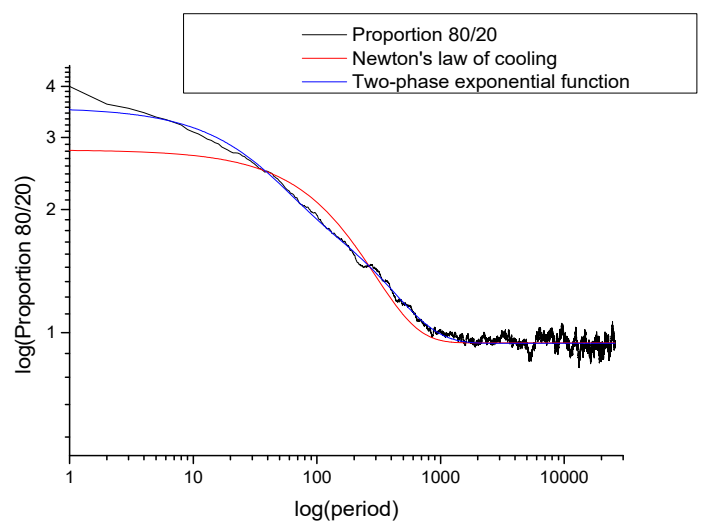

Source: Authors' calculation

\section{Function 5 - Fitted functions for $N=1000$, fix $=5$}

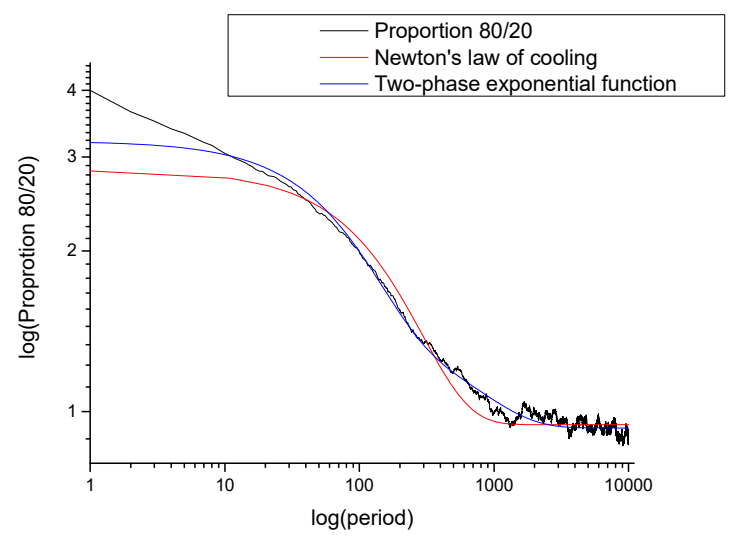

Source: Authors' calculation

Based on the figures 1 to 5 , it can be concluded that the analysed functions describe the data changes in an adequate manner. Although, the two-phase exponential function is better fitted in relation to Newton's law of cooling and better describes the dynamics of change in the proportion, the problem remains at the initial part (in figure 1 up to the first 100 periods, in figure 2, 4, and 5 up to the 10 periods, while in figure 3 the dynamics follows the trend, but there is a difference between the data and function), where a lot of function values differ from the real values. In the last period, when the system reaches a stable phase (equilibrium) both functions have similar values, i.e. there is a $1 \%$ deviation between the values of the two functions. 
Table 1 and 2 shows the results of fitting presented on the five graphics, which are analysed in the case of the first trading rule option.

Table 1 - The values of the parameters of Newton's law of cooling function

\begin{tabular}{|c|c|c|}
\hline $\mathrm{N}=300$, fix $=1$ & & \\
\hline Parameter & Value & Error \\
\hline $\mathrm{T}$ & 1.09639 & $4.18889 \mathrm{E}-4$ \\
\hline $\mathrm{T}_{\mathrm{o}}$ & 3.02525 & 0.00237 \\
\hline $\mathrm{K}$ & $2.92236 \mathrm{E}-4$ & $5.6181 \mathrm{E}-7$ \\
\hline $\mathrm{R}^{2}$ & 0.96609 & \\
\hline \multicolumn{3}{|l|}{$\mathrm{N}=300$, fix $=5$} \\
\hline Parameter & Value & Error \\
\hline $\mathrm{T}$ & 0.91266 & $3.38642 \mathrm{E}-4$ \\
\hline $\mathrm{T}_{\mathrm{o}}$ & 2.6204 & 0.00811 \\
\hline $\mathrm{K}$ & 0.00364 & $2.46051 \mathrm{E}-5$ \\
\hline $\mathrm{R}^{2}$ & 0.68763 & \\
\hline \multicolumn{3}{|l|}{$N=300$, fix $=10$} \\
\hline Parameter & Value & Error \\
\hline $\mathrm{T}$ & 0.94397 & $3.35655 \mathrm{E}-4$ \\
\hline$T_{0}$ & 2.91165 & 0.01918 \\
\hline $\mathrm{K}$ & 0.01965 & $2.69483 \mathrm{E}-4$ \\
\hline $\mathrm{R}^{2}$ & 0.34925 & \\
\hline \multicolumn{3}{|l|}{$N=600$, fix $=5$} \\
\hline Parameter & Value & Error \\
\hline $\mathrm{T}$ & 0.94309 & $2.73855 \mathrm{E}-4$ \\
\hline $\mathrm{T}_{\mathrm{o}}$ & 2.79981 & 0.00608 \\
\hline $\mathrm{K}$ & 0.00487 & $2.27746 \mathrm{E}-4$ \\
\hline $\mathrm{R}^{2}$ & 0.87778 & \\
\hline \multicolumn{3}{|l|}{$N=1000$, fix $=5$} \\
\hline Parameter & Value & Error \\
\hline $\mathrm{T}$ & 0.94474 & $4.90535 \mathrm{E}-4$ \\
\hline $\mathrm{T}_{\mathrm{o}}$ & 2.83400 & 0.00665 \\
\hline $\mathrm{K}$ & 0.00490 & $2.48876 \mathrm{E}-5$ \\
\hline $\mathrm{R}^{2}$ & 0.94012 & \\
\hline
\end{tabular}

Source: Authors' calculation

According to the obtained results, we can claim that the function adequately describes the dynamics of the proportions' change in time, except in the case of $\mathrm{N}=$ 300 , fix $=10$, where the value of determination coefficient is 0.35 . The scenario in which small number of agents are rapidly exchanging the large amount of money "cools" the system and does not lead to equilibrium. As this model does not allow the option to borrow money, much of the agent population runs out of money too quickly. The ultimate values of the body temperature in all cases revolve around 
$1.0 \pm 0.1$, which indicates that the Pareto principle " $80-20$ " can be applied to this model, i.e. $20 \%$ of the population own $80 \%$ of the total resources.

Table 2 - Values of parameters of the two-phase exponential function

\begin{tabular}{|c|c|c|}
\hline $\bar{N}=300$, fix $=1$ & & \\
\hline Parameter & Value & Error \\
\hline $\mathrm{y}_{\mathrm{o}}$ & 1.06164 & $3.16092 \mathrm{E}-4$ \\
\hline $\mathrm{A}_{1}$ & 1.09513 & 0.00348 \\
\hline $\mathrm{t}_{1}$ & $6,106.42031$ & 18.99261 \\
\hline $\mathrm{A}_{2}$ & 1.32656 & 0.00358 \\
\hline$t_{2}$ & 990.25383 & 4.88224 \\
\hline $\mathrm{R}^{2}$ & 0.99083 & \\
\hline \multicolumn{3}{|l|}{$N=300$, fix $=5$} \\
\hline Parameter & Value & Error \\
\hline $\mathrm{y}_{\mathrm{o}}$ & 0.90784 & $3.13252 \mathrm{E}-4$ \\
\hline $\mathrm{A}_{1}$ & 0.60322 & 0.00829 \\
\hline $\mathrm{t}_{1}$ & 863.1647 & 12.10255 \\
\hline $\mathrm{A}_{2}$ & 1.82367 & 0.01438 \\
\hline $\mathrm{t}_{2}$ & 78.07091 & 1.18575 \\
\hline $\mathrm{R}^{2}$ & 0.75101 & \\
\hline \multicolumn{3}{|l|}{$\mathrm{N}=300$, fix $=10$} \\
\hline Parameter & Value & Error \\
\hline $\mathrm{y}_{\mathrm{o}}$ & 0.9437 & $3,33265 \mathrm{E}-4$ \\
\hline $\mathrm{A}_{1}$ & 1.27281 & 0,03598 \\
\hline $\mathrm{t}_{1}$ & 76.8999 & 2,02702 \\
\hline $\mathrm{A}_{2}$ & 1.59504 & 0,05487 \\
\hline $\mathrm{t}_{2}$ & 8.42707 & 0,5655 \\
\hline $\mathrm{R}^{2}$ & 0.36071 & \\
\hline \multicolumn{3}{|l|}{$N=600$, fix $=5$} \\
\hline Parameter & Value & Error \\
\hline $\mathrm{y}_{\mathrm{o}}$ & 0.94134 & $2.42804 \mathrm{E}-4$ \\
\hline $\mathrm{A}_{1}$ & 1.17436 & 0.01041 \\
\hline $\mathrm{t}_{1}$ & 318.57474 & 2.62112 \\
\hline $\mathrm{A}_{2}$ & 1.43549 & 0.01433 \\
\hline $\mathrm{t}_{2}$ & 36.57485 & 0.72719 \\
\hline $\mathrm{R}^{2}$ & 0.90624 & \\
\hline \multicolumn{3}{|l|}{$\mathrm{N}=1000, \mathrm{fix}=5$} \\
\hline Parameter & Value & Error \\
\hline $\mathrm{y}_{\mathrm{o}}$ & 0.93145 & $3.83075 \mathrm{E}-4$ \\
\hline $\mathrm{A}_{1}$ & 1.78964 & 0.00812 \\
\hline$t_{1}$ & 96.73719 & 0.87049 \\
\hline $\mathrm{A}_{2}$ & 0.49051 & 0.00703 \\
\hline $\mathrm{t}_{2}$ & 704.05048 & 9.24066 \\
\hline $\mathrm{R}^{2}$ & 0.97297 & \\
\hline
\end{tabular}

Source: Authors' calculation 
Regarding the results presented in table 2, it can be concluded that the function appropriately describesthe changes in the proportions in time, except in the case of $\mathrm{N}=300$, fix $=10$, wherein the determination coefficient is 0.36 . Similar to Newton's cooling model, the small number of agents in this case and the large amount of money exchanged too quickly "cool" the system and do not lead to equilibrium. The agent-based models based on thermodynamic principles must have a sufficient number of agents to adequately describe the target model. The ultimate values obtained for the body temperature in all cases revolve around $1.0 \pm 0.1$, the Pareto principle " $80-20$ " applies in this model, i.e. $20 \%$ of the population own $80 \%$ of the total resources. The value of the coefficient of determination obtained using twophase exponential function compared to the previous function shows that a twophase exponential function better describes the change in the value proportion than the function of Newton's law of cooling, while the proportion values in the equilibrium conditions are almost identical.

Figure 6 - Fitted functions for $\mathbf{N}=300$, rand=10

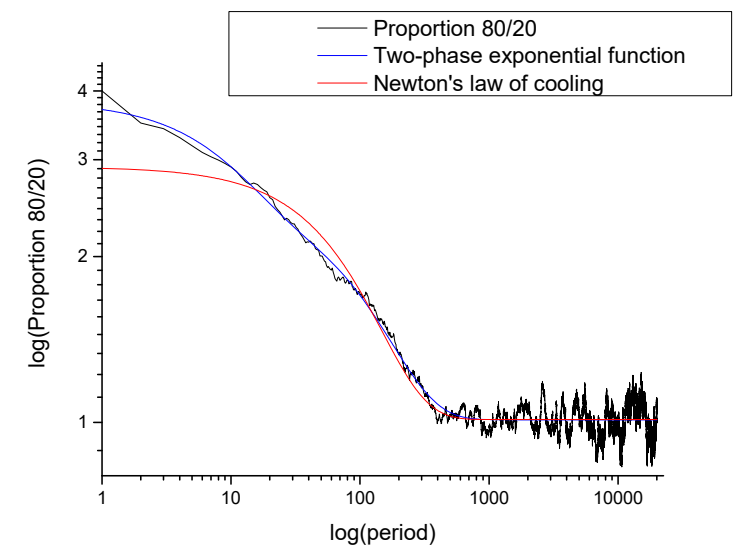

Source: Authors' calculation

Table 3 - The values of the parameters of Newton's law of cooling function

\begin{tabular}{|c|c|c||}
\hline $\mathbf{N}=\mathbf{3 0 0}$, rand $=\mathbf{1 0}$ & & Error \\
\hline Parameter & Value & $5.21372 \mathrm{E}-4$ \\
\hline $\mathrm{T}$ & 1.01138 & 0.01454 \\
\hline $\mathrm{T}_{\mathrm{o}}$ & 2.91158 & $1.05072 \mathrm{E}-4$ \\
\hline $\mathrm{K}$ & 0.00968 & \\
\hline $\mathrm{R}^{2}$ & 0.63110 & \\
\hline
\end{tabular}

Source: Authors' calculation 
In Table 3 we present the values of the model parameters obtained using the twophase exponential function, where agents can randomly choose the sum of money they want to trade within the range of 1 to 10 monetary units. According to the value of the coefficient of determination, we can conclude that the function describes the change in the proportion over the time in a satisfactory manner, while the value of the parameter $T$ indicates that, in this case, when agents cannot borrow money, the Pareto principle can be applied.

Table 4 - Values of parameters of the two-phase exponential function

\begin{tabular}{||c|c|c||}
\hline $\mathbf{N = 3 0 0}$, rand $=\mathbf{1 0}$ & & \\
\hline Parameter & Value & Error \\
\hline $\mathrm{y}_{\mathrm{o}}$ & 1.01085 & $5.13163 \mathrm{E}-4$ \\
\hline $\mathrm{A}_{1}$ & 1.32484 & 0.04936 \\
\hline $\mathrm{t}_{1}$ & 10.66594 & 0.73043 \\
\hline $\mathrm{A}_{2}$ & 1.49518 & 0.02426 \\
\hline $\mathrm{t}_{2}$ & 129.3892 & 2.16769 \\
\hline $\mathrm{R}^{2}$ & 0.64532 & \\
\hline
\end{tabular}

Source: Authors' calculation

The values of the parameters obtained by implementation of the two-phase exponential function model, where agents can randomly choose the sum of money they want to trade with, in the range of 1 to 10 monetary units, are presented in table 4 . According to the coefficient of determination, it can be concluded that the function describes adequately the change of the proportion over the time, while the value of the parameter $T$ indicates that in this case (the second trading option) the Pareto principle can be applied. Compared to the previous one, this function better describes the changes that occur in the system, while the values of proportions, when the system is in equilibrium, obtained by both models are nearly identical (the error is $0.05 \%$ ).

Figure 7 - Fitted functions for $\mathrm{N}=\mathbf{3 0 0}$, rand=10, debt

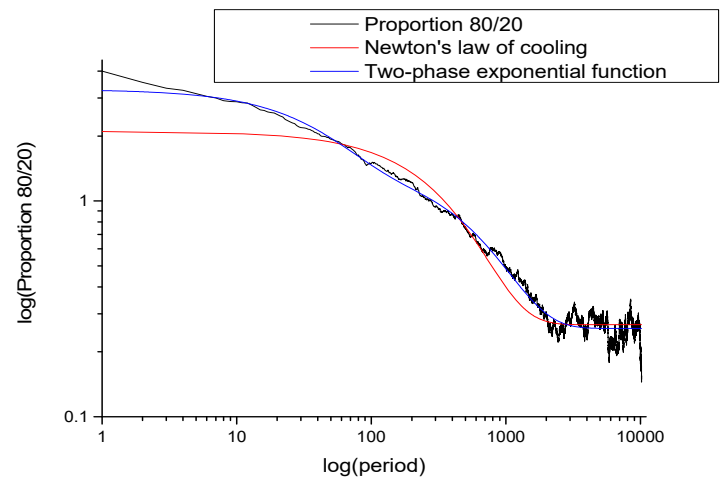

Source: Authors' calculation 
Figure 8 - Fitted functions for $\mathrm{N}=600$, rand $=10$, debt

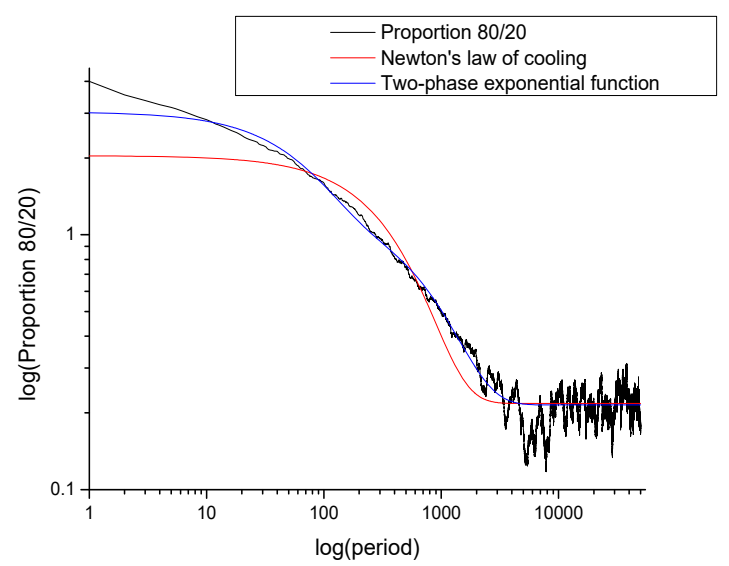

Source: Authors' calculation

Figure 9 - Fitted functions for $\mathrm{N}=1000$, rand=10, debt

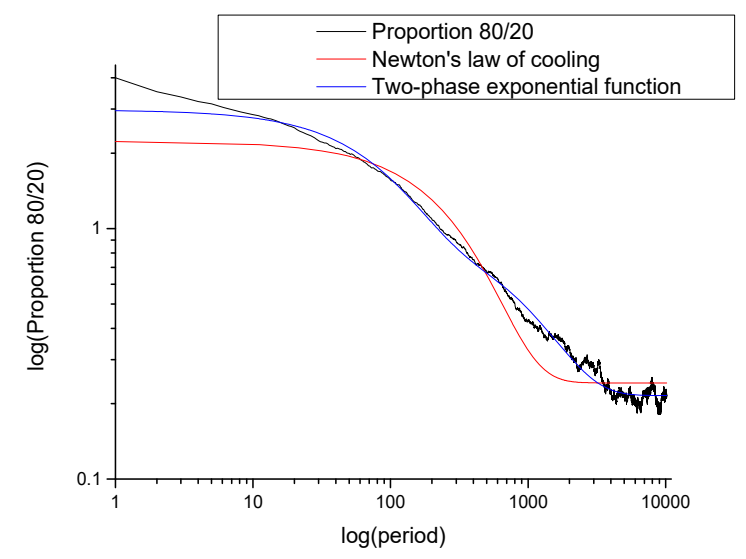

Source: Authors' calculation

The graphs 7 to 9 show the fitted functions of the model that is based on the assumption that agents are allowed to borrow money from the banks up to the initial amount of money. According to the graphics and indicators of the model presented in table 5, it can be stated that Newton's law of cooling function adequately describes the change in the proportion over time, while the value of the parameter $T$ indicates that in the equilibrium state the Pareto principle " $80-20$ " cannot be applied. Instead, it changes to " $90-20$ ", i.e. $20 \%$ of the population own $90 \%$ of the total of money of that population. 
Table 5 - The values of the parameters of Newton's law of cooling function

\begin{tabular}{|c|c|c|}
\hline $\mathrm{N}=300$, rand $=10$, debt & & \\
\hline Parameter & Value & Error \\
\hline $\mathrm{T}$ & 0.26730 & $7.20156 \mathrm{E}-4$ \\
\hline $\mathrm{T}_{\mathrm{o}}$ & 2.10222 & 0.00694 \\
\hline $\mathrm{K}$ & 0.00263 & $1.46459 \mathrm{E}-5$ \\
\hline $\mathrm{R}^{2}$ & 0.92813 & \\
\hline \multicolumn{3}{|l|}{$\mathrm{N}=600$, rand $=10$, debt } \\
\hline Parameter & Value & Error \\
\hline $\mathrm{T}$ & 0.21775 & $1.96717 \mathrm{E}-4$ \\
\hline $\mathrm{T}_{\mathrm{o}}$ & 2.04290 & 0.00416 \\
\hline $\mathrm{K}$ & 0.00230 & $7.48067 \mathrm{E}-6$ \\
\hline $\mathrm{R}^{2}$ & 0.88389 & \\
\hline \multicolumn{3}{|l|}{$\mathrm{N}=1000$, rand $=10$, debt } \\
\hline Parameter & Value & Error \\
\hline $\mathrm{T}$ & 0.24221 & $7.2294 \mathrm{E}-4$ \\
\hline $\mathrm{T}_{\mathrm{o}}$ & 2.23220 & 0.00773 \\
\hline $\mathrm{K}$ & 0.00315 & $1.78867 \mathrm{E}-5$ \\
\hline $\mathrm{R}^{2}$ & 0.92530 & \\
\hline
\end{tabular}

Source: Authors' calculation

Table 6 - Values of parameters of the two-phase exponential function

\begin{tabular}{|c|c|c|}
\hline $\mathrm{N}=300$, rand $=10$, & & \\
\hline Parameter & Value & Error \\
\hline $\mathrm{y}_{\mathrm{o}}$ & 0.25669 & $3.91201 \mathrm{E}-4$ \\
\hline $\mathrm{A}_{1}$ & 1.19902 & 0.00501 \\
\hline$t_{1}$ & 603.42448 & 2.85987 \\
\hline $\mathrm{A}_{2}$ & 1.83829 & 0.01069 \\
\hline $\mathrm{t}_{2}$ & 44.57593 & 0.47867 \\
\hline $\mathrm{R}^{2}$ & 0.98143 & \\
\hline \multicolumn{3}{|c|}{$\mathrm{N}=600$, rand $=10$, debt } \\
\hline Parameter & Value & Error \\
\hline $\mathrm{y}_{\mathrm{o}}$ & 0.21481 & $1.49491 \mathrm{E}-4$ \\
\hline $\mathrm{A}_{1}$ & 1.79817 & 0.00811 \\
\hline $\mathrm{t}_{1}$ & 71.7227 & 0.62241 \\
\hline $\mathrm{A}_{2}$ & 1.02352 & 0.00466 \\
\hline$t_{2}$ & 794.41294 & 3.67160 \\
\hline $\mathrm{R}^{2}$ & 0.93535 & \\
\hline \multicolumn{3}{|c|}{$\mathrm{N}=1000$, rand $=10$, debt } \\
\hline Parameter & Value & Error \\
\hline $\mathrm{y}_{\mathrm{o}}$ & 0.21554 & $3.34946 \mathrm{E}-4$ \\
\hline $\mathrm{A}_{1}$ & 2.02749 & 0.00577 \\
\hline $\mathrm{t}_{1}$ & 94.30033 & 0.52759 \\
\hline $\mathrm{A}_{2}$ & 0.73498 & 0.00364 \\
\hline$t_{2}$ & 967.87363 & 5.26021 \\
\hline$\overline{\mathrm{R}^{2}}$ & 0.98933 & \\
\hline
\end{tabular}

Source: Authors' calculation 
The values of the model parameters presented in the table 6 indicate that the twophase exponential function describes appropriately the proportion change in time, while the value of the parameter $T$ indicates that in the equilibrium phase, we cannot apply the Pareto principle " $80-20$ " because it changes to " $90-20$ ". In comparison to Newton's law of cooling function, we can state that this function in more adequate manner describes the change in the proportion during the time. Moreover, the proportion, when the system is in equilibrium phase, are nearly identical in both models, the error ranges between 1 and 12\%.

\section{Conclusion}

The problem of wealth distribution and its dynamics gathers the great attention of researchers, economists as well as physicists, mathematicians and econophysicsts. Numerous models, that describe the distribution of wealth, are developed, starting from the Pareto model, over the Lorenz curve and Gini coefficient, to econophisics models such as the Boltzmann-Gibbs model. In this paper a stochastic agent-based model based on the classical kinetic wealth exchange model is implemented. The agents are homogeneous and have identical behavior, they randomly interact and exchange some of their monetized wealth.

An interesting problem is the dynamics of change of the wealth distribution between the richest people and the rest of the population. According to the simulations performed in this study, we found that, after a certain time and certain number of interactions between agents, the system itself led to the equilibrium state respecting the three basic principles of balance:

1. Behaviour of agents is consistent - during the process agents respect the predefined rules,

2. No agent has the initiative to change their behaviour - agents continue the process of trading according to the specified trading rules,

3. The equilibrium state is the result a dynamic process, i.e. the exchange processes between agents.

We found that exponential decreasing function might well describe the dynamics of wealth proportions, especially in the models without the possibility of borrowing money, and the validity of the Pareto principle " $80-20$ " in these models could be confirmed. In the models with the possibility of borrowing, the Pareto principles changes to "90-20". We tested two models: the one-phase exponential model in the form of Newton's law of cooling and the two-phase exponential model, and found that the two-phase exponential model more adequately described the dynamics of the wealth distribution then the other one.

In addition to the fact that the implemented agent-based model is rather simplified and the behavior of the agents can be characterized as unrealistic, the research in this paper shows that even such models emerge some macro-level 
features that are also observed in real economic systems. The research in this paper also provides a basis for defining more complex models and draws attention to the fact that some complex resultant traits in the agent-based models can occur with simple homogeneous agents, for example, lacking the ability to predict, learn, maximize profits and other complex traits present in real economic systems.

Acknowledgement: The paper is a part of the research done with the support of the Erasmus + Programme of the European Union within the project no. 611831EPP-1-2019-1-RS-EPPJMO-MODULE.

\section{References}

Benhabib, J., \& Bisin, A. (2018). Skewed wealth distributions: Theory and empirics. Journal of Economic Literature, 56(4), 1261-91.

Chiu, Y. F., Chen, Y. H., Roncel, M., Dilbeck, P. L., Huang, J. Y., Ke, S. C., ... \& Chu, H. A. (2013). Spectroscopic and functional characterization of cyanobacterium Synechocystis PCC 6803 mutants on the cytoplasmic-side of cytochrome b559 in photosystem II. Biochimica et Biophysica Acta (BBA)-Bioenergetics, 1827(4), 507-519.

Desai, D. A. (2006). Newton's law of cooling. Physics Education, 23(1), 51-54.

Dixon, H. (1990). Equilibrium and Explanation. In Creedy, J. (ed.), The Foundations of Economic Thought. Oxford: Blackwells. pp. 356-394. ISBN 0-631-15642-9. (reprinted in Surfing Economics).

Drăgulescu, A., \& Yakovenko, V. M. (2001). Exponential and power-law probability distributions of wealth and income in the United Kingdom and the United States. Physica A: Statistical Mechanics and its Applications, 299(1-2), 213-221.

Dunford, R., Su, Q., \& Tamang, E. (2014). The Pareto Principle. The Plymouth Student Scientist, 7(1), 140-148.

Gkranas, A., Rendoumis, V. L., \& Polatoglou, H. M. (2004). Athens and Lisbon stock marketsA thermodynamic approach. WSEAS Transactions on Business and Economics, 1(1), 95-100.

Hubmer, J., Krusell, P., \& Smith Jr, A. A. (2016). The historical evolution of the wealth distribution: A quantitative-theoretic investigation (No. w23011). National Bureau of Economic Research.

Klass, O. S., Biham, O., Levy, M., Malcai, O., \& Solomon, S. (2006). The Forbes 400 and the Pareto wealth distribution. Economics Letters, 90(2), 290-295.

Lewis, M. A. (2010). The Physics of Inflation: Newton's law of cooling and Consumer Price Index. Journal of Applied Quantitative Methods, 5(1).

Leys, T. (2019). The Current State of Agent-Based Modeling. Belgium: University of Antwerp.

Li, Q., Xing, D., Jia, L., \& Wang, J. (2007). Mechanism study on the origin of delayed fluorescence by an analytic modeling of the electronic reflux for photosynthetic electron transport chain. Journal of Photochemistry and Photobiology B: Biology, 87(3), 183190.

Lux, T. (2005). Emergent statistical wealth distributions in simple monetary exchange models: a critical review. In Econophysics of wealth distributions (pp. 51-60). Springer, Milano.

Macal, C., \& North, M. (2010). Tutorial on agent-based modelling and simulation. Journal of simulation, 4(3), 151-162. 
Michel, F., Ferber, J., \& Drogoul, A. (2018). Multi-Agent Systems and Simulation: A Survey from the Agent Community's Perspective. In Multi-Agent Systems (pp. 17-66). CRC Press.

Sorger, G. (2000). Income and wealth distribution in a simple model of growth. Economic Theory, 16(1), 23-42.

Trichet, J. C. (2010). Reflections on the nature of monetary policy non-standard measures and finance theory, Opening address at the ECB Central Banking Conference, Frankfurt, 18 November 2010. https://www.ecb.europa.eu/press/key/date/2010/html/sp101118.en.html

Vollmer, M. (2009). Newton's law of cooling revisited. European Journal of Physics, 30(5), 1063-1084.

Wang, N. (2007). An equilibrium model of wealth distribution. Journal of Monetary Economics, 54(7), 1882-1904.

Wilensky, U. (2020). Netlogo website. https://ccl.northwestern.edu/netlogo/

Wilensky, U., \& Rand, W. (2015). An introduction to agent-based modeling: modeling natural, social, and engineered complex systems with NetLogo. Cambridge: Mit Press.

Wooldridge, M. (2009). An introduction to multiagent systems. Chichester: John Wiley \& Sons.

Xiong, W., Fu, H., \& Wang, Y. (2017). Money creation and circulation in a credit economy. Physica A: Statistical Mechanics and its Applications, 465, 425-437.

Yakovenko, V. M. (2010). Statistical Mechanics of Money, Debt and Energy Consumption. Science and Culture, 430-436.

Zarikas, V., Christopoulos, A. G., \& Rendoumis, V. L. (2009). A thermodynamic description of the time evolution of a stock market index. European Journal of Economics, Finance and Administrative Sciences, 16, 73-83.

\section{DVOFAZNI EKSPONENCIJALNI MODEL DISTRIBUCIJE BOGATSTVA}

Apstrakt: Problem distribucije bogatstva i novca zaokuplja veliku pažnju ekonomista, ali i istraživača iz drugih naučnih oblasti, kao što je statistička fizika i ekonofizika. Kreira se sve veći broj modela i simulacija sa ciljem da se što bolje shvati proces distribucije bogatstva i kako se dolazi do ravnotežnog stanja sistema distribucije. Takođe, sve veći broj radova se bavi i analizom utvrđivanja preovlađujuce proporcije, tako da, za razliku od ranijih godina kada je Pareto princip bio "80-20", danas se na osnovu istraživanja utvrđuje da taj princip glasi “90-10", pa čak i "90-20". U ovom radu prezentovan je model zasnovan na simulaciji za opis dinamike distribucije bogatstva. Testirana su dva modela eksponencijalne funkcije, i to: jednofazni model koji koristi funkciju u obliku Njutnovog zakona hlađenja i dvofazni model sa eksponencijalnom funkcijom. Utvrđeno je da opadajuća eksponencijalna funkcija na adekvatan način opisuje dinamiku raspodele bogatstva, posebno u modelima u kojima ne postoji mogućnost zaduživanja agenata, kao i to da se u ovim modelima može potvrditi Pareto princip " $80-20$ ".

Ključne reči: distribucija bogatstva, eksponencijalna funkcija, Njutnov zakon hlađenja 


\section{Authors' biographies}

Ognjen Radović, PhD, is an Associate Professor at the Faculty of Economics, University of Niš, Serbia. He graduated from the Faculty of Electronics, University of Niš in 1992 and received his M.Sc. degree (2003) from the Faculty of Economics at the University of Niš. He received his Ph.D. degree (2011) from the Faculty of Economics in Subotica at the University of Novi Sad. He teaches Informatics, Business Information Systems and Electronic business at the Faculty of Economics, University of Niš.

Zoran Tomić received the BSc and MSc degrees in economics from the Faculty of Economics, University of Niš, Serbia in 2011 and 2013, respectively. He is currently a $\mathrm{PhD}$ student conducting researches in the field of regional development, public finance, agricultural insurance, as well as econophysics as a new scientific discipline. He works as a teaching assistant at the Agricultural Faculty, University of Niš, in Kruševac. During the studies he was a scholar of the Ministry of Education, Science and Technological Development, Foundation for Young Talents - Dositeja, Foundation of the company Philip Morris International and the Fund for Encouraging the Development of Young Talents of the City of Kruševac.

Jelena Z. Stanković, PhD, is an Assistant Professor at the Faculty of Economics, University of Niš, for the narrow scientific field: accounting, auditing and financial management (teaching courses: Corporate Finance, Risk Management and Insurance, Strategic Financial Management, Financial Strategy of Corporate Enterprises). She is an author and co-author of university textbook, chapters in three international thematic collections of papers and more than 40 papers published in international and national journals and conference proceedings. Her research interests include accounting, corporate finance and valuation and risk management in finance and insurance. 